\title{
Adoption of range management innovations by Utah ranchers
}

\author{
ELIZABETH A. DIDIER AND MARK W. BRUNSON
}

\begin{abstract}
Authors are Assistant Agent, University of Arizona Cooperative Extension, Mohave County, Kingman, Ariz. $86401-5827$ and Associate Professor, Dept. of Environment and Society, Utah State University, Logan, Utah 84322-5215. At the time of this research the senior author was graduate Research Assistant, Dept. of Rangeland Resources, Utah State University.
\end{abstract}

\section{Abstract}

Improving the sustainability of grazed rangelands requires that landowners adopt management innovations. We interviewed Utah ranchers to better understand innovation adoption among range livestock operators, and ultimately to suggest improvements in content and delivery of outreach activities. A 2-phase, qualitative social science research method was used to encourage discovery of information unlikely to be revealed via surveys and to expand the application of adoption theory to range livestock production. In line with previous research, innovation was related to full-time ranch operation, dependence on ranch income, anticipated future of the ranch, and extent of social networks. Barriers to innovation included inadequate time and resources, peer influences, and perceived drawbacks of potential innovations (e.g., difficulty of pilot-testing new grazing systems, or poor cost-benefit ratios of vegetation treatments). In contrast to previous studies, innovators were motivated by a desire to demonstrate stewardship to land managers and the public. Previously unidentified barriers included spatial characteristics of the ranch enterprise and perceptions about political/legal constraints.

Economic hardships, combined with changing political-legal forces and ecological conditions, are threatening the sustainability of Western range livestock production. Not only do marginal ranch operations tend to be at risk ecologically, but as ranches are sold non-grazing uses of rangelands such as subdivision pose additional risks to conservation (Knight et al. 1994, 2002). Enterprise diversification and implementation of improvements are advocated as ways for ranchers to cope with marginal returns from ranching while better managing resources. However, relatively few ranchers make such substantive changes in their operations (Coppock and Birkenfeld 1999). If range professionals are to successfully encourage implementation of desirable management practices, more information is needed about when and why range livestock operators will adopt innovations that can enhance sustainability.

Innovation adoption has been shown to be influenced by characteristics of the individual (e.g., age), innovation (e.g., complexity), and social system (e.g., attitudes of peers) (Rogers 1995). Among agricultural producers, characteristics of the operation such as property size are also important (Bultena and Hoiberg

This research was supported by the Utah Agricultural Experiment Station, Utah State University, Logan, Utah $84322-4810$ as part of the Cedar Mountain Initiative sponsored by the Utah Legislature. Approved as journal paper no. 7503.

Manuscript accepted 11 Sept. 03.

\section{Resumen}

Mejorar la sustenabilidad de los pastizales requiere que los terratenientes adopten innovaciones de la gerencia. Nos entrevistamos a ganaderos de Utah para entender mejor la adopción de las innovaciones para productores, y para sugerir en última instancia mejoras en contenido y entrega de las actividades educacionales. Utilizamos un método de investigación sociológica cualitativa con dos fases para fomentar el descubrimiento de información que probable no sea revelado vía encueastas, y para ampliar el uso de la teoría de la adopción a la producción ganadera en los pastizales. Cómo en investigaciones anteriores, la innovación fue relacionada con la operación del rancho de tiempo completo, la dependencia de los ingresos del rancho, el futuro anticipado del rancho, y la amplitud de los redes sociales. Las barreras a la adopción de las innovaciones incluyeron: tiempo y recursos inadecuados, influencias del grupo paritario, $y$ desventajas aparentes de innovaciones potenciales (par ejemplo, dificultad para probar nuevos sistemas de pasto antes de adoptar, o proporciones desfavorables de costes a provechos para los tratamientos de la vegetación). En contraste con los investigaciones anteriores, innovadores fue motivados para un deseo de demostrar el cuidado de la tierra apropiado a los encargados de los terrenos comunales y al público. Las barreras previamente no identificadas incluyeron las características espaciales de la empresa ganadera y las opiniones de los productores sobre las limitaciones de los sistemas política y legal.

1983). Studies of adoption among farmers (e.g., Bultena and Hoiberg 1983, Nowak and Korsching 1983, Buttel and Swanson 1986, Saltiel et al. 1994) suggest that the adoption process is somewhat different among these individuals because agricultural producers are faced with constraints that serve as barriers to adoption. These constraints stem from market instability, conflicting societal demands for high productivity and environmental sustainability, and unpredictable climatic conditions (e.g., drought) (Kearl 1975, Saltiel et al. 1994). One might expect the process to differ in other ways for western ranchers due to the particular economic pressures created by large holdings of relatively unproductive land and the particular structure of livestock markets, as well as unique values held within the ranching culture. Grigsby (1980) characterizes ranchers as a "unique subculture" within the larger category of agricultural producers, pointing out that they tend to place high value on ranching as a way of life and will often trade monetary profit for the "gain" of maintaining traditional ranching lifestyle. Therefore one might expect 
that the existing theoretical framework of innovation adoption (Rogers 1995), and even the variations elaborated above, may not fully explain adoption within the ranching "subculture."

Relatively little research has explored the adoption process among range livestock producers, and the range science community has a limited understanding of the factors that facilitate or discourage adoption (Coppock and Birkenfeld 1999). Results from past surveys offer some insight (e.g., Lacey et al. 1985, Rowan and White 1994, Coppock and Birkenfeld 1999, Kreuter et al. 2001, Peterson and Coppock 2001, Rowe et al. 2001). Peterson and Coppock (2001) identified advancing age and economics as primary barriers to adoption among Utah ranchers. In Montana, Lacey et al. (1985) found that when investment in range improvements occurs, it tends to be made by operators of larger ranches, and ranchers are more likely to invest in structural improvements (e.g., fencing or water developments) rather than nonstructural improvements (e.g., range reseeding). Research in Utah (Coppock and Birkenfeld 1999) and Colorado (Rowe et al. 2001) has revealed that diversification of the enterprise is not a popular management option among livestock producers.

Previous research suggests that rates of innovation adoption by ranchers may be lower in Utah than elsewhere (Coppock and Birkenfeld 1999). In fall/winter 2001-02, we conducted interviews of Utah ranchers to expand the current understanding of adoption. The ultimate aim was to suggest improvements in content and delivery of education that could help the state's ranchers evaluate options for improving the sustainability of their rangelands. Whereas previous studies of this topic in Utah identified attributes useful for predicting which producers would change their management practices (Coppock and Birkenfeld 1999, Peterson and Coppock 2001), we focused specifically on those producers who have been identified as innovators. Our research objectives were: (1) to identify characteristics common to innovators/early adopters in the Utah ranching community and (2) to explore those ranchers' motivations for adopting new practices and perceptions about barriers to adoption.

\section{Methods}

\section{Research approach}

To explore range innovation in depth, we chose a qualitative methodology that could facilitate the discovery of information unlikely to be brought forth by surveys such as those employed in previous studies of the topic. Survey research is popular for studying natural resource issues for several reasons: (1) population parameters can be quantified, (2) analytical tools are well defined and can be used to provide generalizations about the population under study, (3) variance of key parameters and the degree of confidence associated with hypotheses can be estimated, (4) replication and validation are relatively easy when standardized procedures are used, and (5) the survey method is generally accepted by the scientific community (Bliss and Martin 1989). However, the survey method is not without weaknesses. It can inhibit discovery about littlestudied topics, because survey researchers must predetermine questions along with an appropriate range of responses to include in a survey instrument. Typically results of past research or pre-survey interviews are used to identify an "appropriate" range of responses for multiple-choice questions, but this can foreclose opportunities for respondents to express their own views or motivations (Bliss and Martin 1989). Moreover, the survey protocol cannot be adapted throughout the process. Even if the researcher learns new information or realizes a need to gather more complete answers to certain questions, the survey instrument must be rigidly maintained to facilitate statistically sound analysis (Babbie 1989).

In contrast, qualitative research is notable for its openness and flexibility (Strauss and Corbin 1990). Hypotheses are not predetermined, and questions can be modified along the way, so that changes can be made to a study in progress as new and unexpected information is discovered. During an indepth personal interview a researcher can revisit certain questions with a different approach to obtain a better understanding of the response and clarify questions that the respondent may not fully understand. The unexpected information that this approach can discover may make the innovation adoption theory more robust.

In order to test hypotheses, surveys tend to focus on population traits or "statistical aggregates" rather than individuals
(Bogdan and Taylor 1975, Bliss and Martin 1989). This is appropriate to produce an estimate of the "average" (Bliss and Martin 1989), but when there is a need to understand individual behavior it is useful to examine concepts as they are defined and experienced by "real people," rather than as researchers theorize (Bogdan and Taylor 1975). Developing a deeper understanding of the adoption process among ranchers required that the boundaries of the existing theoretical framework be expanded and the behavior of individual ranchers explored.

Researchers sometimes are reluctant to employ qualitative methods for several reasons. Qualitative research generates an overwhelming amount of data. Studies are difficult to replicate, and generalizability is often low due to selective sampling (Babbie 1989, Bliss and Martin 1989, Henderson 1991). Another limitation is that methods of analysis have not been well defined (Patton 1980, Miles 1983, Yin 1994), so the task depends largely on "sufficient presentation of the evidence and careful consideration of alternative interpretations" (Yin 1994). While these problems require careful attention by the researcher, they are manageable if a study is properly designed.

One of the most difficult problems for researchers is that qualitative studies are generally not well accepted by the scientific community, especially by persons unfamiliar with the full range of social research methods. Qualitative research is said to be "soft" (Bliss and Martin 1989), and fellow scientists have a "tendency to fret over matters of design - notably sampling, validity and generalizability - and tend to minimize the importance of the original ideas that have just been brought to light" (Stebbins 2001). This is unfortunate, because even though useful information can be discovered through qualitative techniques, researchers are understandably reluctant to risk their work being dismissed in this way (Downey and Ireland 1983).

The qualitative methodology for this study was guided by grounded theory (Glaser and Strauss 1967), an inductive approach through which the researcher begins with observations and then identifies patterns. Although a researcher may have ideas about what will be found, formal hypotheses are not formed. According to Babbie (1999), this kind of an approach allows "greater latitude for discovering the unexpected." The purpose of grounded theory is to identify conceptual categories 
or properties that can make an existing theory more robust (Glaser and Strauss 1967). The theoretical framework for innovation adoption provided by Rogers (1995) was used to guide question formation, but we followed a grounded theory approach in our interview methods to avoid imposing a rigid protocol that would only allow existing theory to be tested.

\section{Phase I: Key Informant Interviews}

There were 2 research phases. Informal qualitative interviews were conducted with key informants (i.e., Utah State University Extension agents, Natural Resources Conservation Service (NRCS) employees, and livestock producers) in Spring 2001. The goal of the interviews was to allow the respondents to express their personal perceptions about changes Utah ranchers were making or were interested in making to their operations. Also discussed were reluctance to adopt and motivations for adopting new practices. An interview protocol was developed, and a strong effort was made to keep interviews conversational with the use of openended questions. The purpose of Phase I was to discover information to guide the primary research. Therefore, data were not analyzed in-depth. Interview notes were reviewed and summarized, and we compared the data to the existing innovation adoption literature.

Particularly relevant to our decision about the primary research method was a pervasive belief among our Phase I informants that there was very little adoption of range management practices in Utah (see Results and Discussion). Respondents felt that many ranchers were pessimistic about the future of ranching and that this pessimism served as a barrier to innovation. Accordingly we chose to focus on the relatively few ranchers who were considered innovators, in order to identify characteristics of the ranchers or their operations that could be useful in encouraging innovation adoption among a wider group of their peers. Innovative ranchers were determined to be appropriate respondents because they are familiar with the adoption process as well as barriers to adoption, and we suspected that they were somewhat unique because they continue to invest in improvements even as their peers take a passive or fatalistic view of their operations.

\section{Phase II: Rancher Interviews}

Given what we learned in Phase I, indepth interviews were conducted among a sample of ranchers in Fall/Winter 2001-02. A list of the state's most innovative producers was built by asking NRCS and Extension professionals and stockgrowers' organizations to provide names of livestock producers known for adopting management practices intended to enhance the environmental and economic sustainability of their ranches. The different groups were consulted in an effort to reduce selection bias. A total of 34 names were collected. Appropriate respondents were selected from the list by contacting producers to make sure they were using practices that qualified for the study as well as willing to participate in a face-toface interview.

The interviews were focused-i.e., questions were guided by the adoption-diffusion theoretical framework developed by Rogers (1995) - but also semi-structured, designed to be "open-ended and conversational in manner" as recommended by Yin (1994). A 31-question interview protocol provided a basic framework for each interview, however questions were not asked in the same order nor in the same way for every interview. This approach kept the interviews fresh and encouraged the discovery of unanticipated information, but ensured that each interview touched on all of the topics in the interview guide. Included in the guide were questions asking interviewees to describe changes they had made, their motivations for change, and reasons for not implementing other changes. Personal characteristics, potential innovations (e.g., diversification of the ranch with a fee hunting operation), local social system, and ranch structure were explored as factors related to adoption.

Fifteen interviews averaging 1 hour each were completed, which means that $44 \%$ of persons in the identified population of innovators were interviewed. The sample size was guided by the criterion of "saturation,' i.e., new interviews were initiated until new information was no longer encountered (Glaser and Strauss 1967). Interviews were recorded and transcribed, and data were analyzed using a combination of the explanation-building ( $Y$ in 1994) and constant comparative coding methods (Glaser and Strauss 1967).

\section{Results and Discussion}

\section{Phase I: Key Informant Interviews}

Key informants believed Utah ranchers most commonly invest in improvements such as brush management, fencing, and water developments. Adoption of intensive rotational grazing systems and rangeland monitoring practices was said to be rare. Respondents felt that ranchers innovate in order to protect soil, water, wildlife, and forage resources and to improve productivity/profitability. According to some range professionals, ranchers will sometimes implement practices such as monitoring to protect themselves from a threat to their ranching livelihoods or to defend their management.

Phase I interviews also explored barriers to innovation. Not surprisingly given the findings of Peterson and Coppock (2001), respondents identified limited time and income as barriers to adoption. Strong commitments to traditional ranching practices were also cited as reasons for nonadoption, which is compatible with previous research findings that ranchers trade income for lifestyle benefits (Smith and Martin 1972, Grigsby 1980). Utah's settlement pattern, heavily influenced by the utopian vision of early Mormon leadership (Grey 1978) that encouraged ranchers to live in town rather than out on their ranchland, emerged as a barrier because living away from the ranch makes managementintensive practices more difficult to implement. This is especially true when ranchers experiencing low returns from livestock production must hold a full-time job in town. Furthermore, travel time between different parts of a ranch can be substantial due to the checkerboard land ownership patterns common in the West.

Respondents also discussed the perception that it is risky for ranchers to invest in change when they are uncertain about the future of their operations. Innovation on public grazing allotments was said to be limited by concerns that the land might not be available for subsequent grazing due to political changes exemplified by designation of the Grand Staircase-Escalante National Monument in 1996.

In addition to barriers described above, barriers specific to diversification activities such as fee hunting were identified. Respondents felt that some ranchers are reluctant to diversify because (1) they are concerned about the liability and hassle connected with dealing with the public, (2) 
they anticipate problems associated with partnering with adjacent landowners to establish hunting businesses (e.g., partners allowing friends and family members to hunt for free), and/or (3) the location of the operation can limit diversification opportunities (e.g., a ranch may experience heavy ungulate use in the spring, but the animals are not present during the hunting season).

\section{Phase II: Rancher Interviews Respondents}

Because this study used a selective sampling technique, it is important to understand how the respondents fit into Utah's ranching population. Coppock and Birkenfeld (1999) described the heterogeneity of Utah's ranching community, identifying 5 socioeconomic subgroups having different resources, goals, and vulnerability to changes in federal land policy. Most of our interviewees belong to the group Coppock and Birkenfeld (1999) called "Ranchers." This group was described as being reliant on income from livestock production and dependent on family labor, with medium-sized operations, and holding traditional ranching values. In 1999, "Ranchers" represented approximately $35 \%$ of Utah federal grazing permit-holders (Coppock and Birkenfeld 1999). "Ranchers" are likely to be an especially important group for range professionals to work with because they are a large enough group to have a significant impact on Utah's rangelands, and traditional enough to be respected and influential within a wide segment of the ranching community.

\section{Motivations for Adoption}

Phase II respondents confirmed that they have made innovations for each of the reasons identified in Phase I, but richer detail allowed for a deeper understanding of these motives. For example, the ranchers said they adopt practices to improve profitability and conserve natural resources, and they often emphasized the link between those goals. Interviewees expressed strong lifestyle and land stewardship values that influenced their decisions to invest in improvements. In some cases, ranchers invested in conservation practices even when they did not expect to recover costs associated with implementation.

Some of it you do because you know it's good for the land and good conservation. ...you're saving topsoil and resources ... [the improvements] cost you money, but in the long haul, it's improvement on the land.

A motive not discussed in Phase I interviews or previous research was that ranchers innovate to demonstrate good land stewardship to the public and to improve relationships with public land management agencies. While Grigsby (1980) suggested that lifestyle-oriented ranchers would reject collaborative efforts, government intervention, and innovation because those things interfere with ranching values, active involvement in such activities may be a lifestyle maintenance strategy in today's changing socio-political environment, even among ranchers who possess traditional ranching lifestyle values.

I think if we can maintain and show that we're taking very good care of the range, and these improvements are enhancing the range, then we can say, 'look, we're being good stewards here. ... The more you can do to help maintain the rangeland just adds to your side of the equation to keep you out there.

\section{Personal Characteristics}

The interviewees were full-time ranchers with few off-ranch obligations, and most lived on or very near the ranch. In these ways, the interviewees differ from many Utah ranchers who work off-ranch jobs and live in town. Some of these ranchers said that because they do not work off-ranch jobs or have to commute to and from the ranch, they have more time to devote to innovation. Each respondent said his family was dependent primarily on ranch income, and for the most part interviewees belong to multi-generational ranching families. These factors may help explain why these ranchers continue to invest limited financial resources to improving the operation. A Texas survey revealed that level of dependence on ranching income influenced decisions to invest in improvements (Rowan and White 1994), but this idea has otherwise rarely appeared in adoption literature.

Each respondent also demonstrated a strong commitment to ranching for the rest of his life, and most expected the ranch to continue for at least 1 more generation.

I guess just because [the ranch has] been in the family so long, I can't see anything but it remaining in the family to operate in at least some form as a ranch. ... it may be a dude ranch or something different than it is now, but we'll still be on the land ... at least for another generation.

These findings illustrate strong ranching lifestyle values among respondents and may explain why they may be more willing to continue investing in improvements than are producers who believe their ranches will be sold and subdivided in the near future. In part, this confidence in the future of the ranch may reflect the fact that several interviewees have no public land grazing leases. Of those who graze on public lands, some stated that while public grazing was extremely important to them, they would find a way to continue ranching if access to public lands was reduced. Similar commitment to ranching was illustrated by results of a Colorado survey, which revealed that ranchers dependent on ranching income and public lands were determined to stay on the ranch regardless of reductions in federal grazing privileges (Rowe et al. 2001). Innovative management inspired by these values may allow ranchers who otherwise might be forced out of the business by such events to sustain their operations.

Rogers (1995) suggests that individuals with large social networks are more likely to innovate. This was affirmed in our study. Interviewees reported widespread social interactions and said they actively seek information about range management, especially from university extension and ranching organizations.

There are a lot of contacts we've made through the National Cattlemen's, you know, people from all over the country ... you get a lot of ideas that way.

Due to these interactions, these ranchers may be more comfortable trying new things than producers who are not commonly exposed to innovative ideas and people. This kind of contact also allows ranchers to observe outcomes produced when others innovate, which is consistent with Rogers' (1995) hypothesis that people are more likely to adopt practices when they can readily observe the results. This reduces the risk associated with making a change. As one respondent stated:

I'm not a risk-taker. We're open to looking at doing things, but we usually study it long enough to make sure it's going to work before we try it. ... 


\section{Barriers to Adoption}

Even though we focused on Utah's most innovative ranchers, interviewees reported obstacles to adoption. As theory predicted, characteristics of the individual, innovation, social system, and ranch were identified as barriers to innovation, although ranch characteristics that had not been explored by other researchers surfaced as barriers among Utah ranchers. In a finding not specifically reported by other researchers, characteristics of the politicallegal system in which ranchers operate were also found to constrain adoption.

Personal characteristics of the interviewees positively related to adoption in many ways, but certain characteristics seem to be barriers to adoption. Time and money, identified as barriers in Phase I, were also discussed during in-depth interviews. Adoption is sometimes slowed as ranchers wait for time and money to become available for innovation and as they wait for uncertainty associated with adoption to decrease. Time constraints were particularly important when ranchers talked about diversifying their operations with recreation enterprises.

...I think we could do more with recreation, running the dudes or camping or yurts or cabins or whatever. All you need is time and money, or people to do it. ... it takes somebody full-time to tend to the public.

Respondents confirmed that commitments to traditional ranching lifestyles reinforced a reluctance to adopt certain innovations, particularly recreation enterprises.

It's mainly [that] just we kind of like being by ourselves out there, so just having people around is kind of a bother. We're kind of used to having the place to ourselves. [Adding a recreation enterprise] is something we can do if we need to, I guess we just haven't gotten to that point yet.

Even some ranchers who are currently involved in the recreation business said that they would prefer to concentrate on traditional ranching activities such as livestock production. The choice not to diversify the operation with a non-traditional business is consistent with Grigsby's (1980) finding that ranchers will trade profit for lifestyle maintenance.

Rogers (1995) identifies 5 characteristics of innovations that influence adoption: relative advantage, compatibility, com- plexity, trialability, and observability. Theoretically, ranchers will be more likely to adopt innovations that are perceived to (1) have clear relative advantage over old management practices, (2) are compatible with operational goals, (3) are less complex, (4) are able to be tested on a smallscale prior to adoption, and (5) quickly produce observable results. Interview results showed how each of these characteristics affects adoption. For example, relative advantage was important when ranchers made decisions to invest in vegetation management practices. Due to the low productivity of arid rangelands and marginal returns from livestock production, some producers were uncertain of the advantages of investing in these types of improvements. One interviewee suggested that at the current per-acre cost of herbicides, "you're buying the land over again on rangeland at that price."

Ranchers also discussed how running a fee hunting business is somewhat incompatible with livestock production.

...the big problem we have with

[fee hunting] is hunting season is also cow-gathering season.

Moreover, diversification of the ranch necessarily increases the complexity of the operation, whereas other innovations may not do so.

As another example, respondents said that intensive rotational grazing systems are difficult to adopt because they are difficult to test on a small-scale prior to adoption (i.e., they do not possess a high degree of trialability) and do not have clear relative advantage.

We just didn't know if [intensive rotational grazing] was going to work any better than what we'd been doing. ... once you put up the fences, you're kind of committed.

Grigsby (1980) argues that non-adoption of innovations among ranchers is not always attributable to a lack of information. In our study, respondents said they had received information about intensive rotational grazing systems but were not convinced they would be more beneficial than current practices. Additionally, this particular innovation was incompatible with some ranchers' values because, as with fee hunting, adoption requires a lifestyle change (i.e., increased management input). One rancher noted that he can "only do so much" because he gets to spend too little time with his family.
The traditional nature of the ranching social system serves as a barrier to adoption. During in-depth interviews, ranchers described how others in the social system react to innovation.

Most of the other producers don't think too highly of [dude ranching]. ...everybody just kind of says,

'that's not real ranching,' you know.

Ranchers may be unlikely to innovate when their peers do not approve. Especially if they are dedicated to maintaining their ranching lifestyles, it may be difficult to cope with having their activities being labeled as "not real ranching" by other members of the ranching culture.

A characteristic of the social system rarely mentioned in the adoption-diffusion literature consists of barriers associated with the political-legal system in which ranchers operate. For example, while ranchers formerly had access to a variety of cost-share programs, the NRCS Environmental Quality Incentives Program (EQIP) has become a primary source of cost-share funds. Several producers described the importance of these funds in making improvements to their rangeland and said that having access to EQIP funds reduces the risk of investing in innovation. One producer spoke of having to delay vegetation treatments until he could qualify for cost-sharè assistance. Another felt that EQIP funds seemed to be distributed to fewer producers working on large projects; when the money was distributed to more producers, more conservation projects were implemented.

When we spread the money out thinner, to more producers, we got more conservation done than we do now. ... There's less people getting a piece of the pie there. There's less producers getting conservation money.

This statement suggests a perception among producers that it might be difficult to qualify for cost-share funds. In actuality the EQIP formula was adjusted in 2000 to make funds more widely available (L. Ellicott, NRCS, pers. comm.), but if the perception is common among ranchers that cost-share funds are disbursed to producers working on large projects, they may feel that the chances of receiving assistance are low and thus may be reluctant to innovate.

Producers also expressed concern about how adjacent public lands are managed, particularly as it affects competition for 
forage with wild ungulates. Two interviewees suggested that improving their own pastures would merely attract elk from adjacent public lands in relatively poorer condition. Another respondent was discouraged from making improvements on public land because, after he invested in improving part of his public allotment in the past, elk were attracted to the area and the management agency decided the area could no longer be used for livestock grazing.

Interviewees also were discouraged by government regulations that slow the implementation of improvements, especially when they felt that the environmental benefits of the improvement were obvious.

...we've put in a lot of gully plugs to stop erosion. And we had to wade through [US Army] Corps of Engineers red tape... And so, they've cost us a lot of time. And there's still a lot of erosion things that need to be done up there, but I haven't had time to wade through the red tape. ... it gets discouraging when you're trying to make improvements, and even they know it's an improvement, and yet they want you to go through all this rigmarole.

Concerns about the liability associated with running a recreation enterprise also emerged in both preliminary and in-depth interviews as a barrier to diversification.

...[W] e've looked into [dude ranching]. ... But whenever you're dealing with the public, you've got a liability issue, and at this time I'm not saying in the future, but at this time - the liability insurance would kill us. I don't know how I'd handle the public. And that's the reason I don't want to get into [fee hunting], because it seems to be a sue-society.

In the past when researchers have examined how characteristics of the operation relate to innovation adoption in agriculture, operation size and managerial aspects have been most commonly explored (Bultena and Hoiberg 1983, Lacey et al. 1985). Ranchers interviewed for this study operated on ranches of all sizes, so size appeared not to be an important factor influencing adoption. Likewise Peterson and Coppock (2001) found that operation size was not an important indicator of innovativeness. Instead, we found that spatial arrangement of Utah ranches negatively affects innovation adoption. This is an example of how a new element is added to an existing conceptual category within the theoretical framework.

Utah, like most Western states, is characterized by a discontinuous pattern of public and private land ownership (i.e., "checkerboard pattern"). Interviewees described problems associated with the scattered distribution of their ranch lands and with trying to implement improvements on parcels of land not owned by one agency.

... It's hard to find enough ground

all together here that's not got somebody else right in the middle to make an economical unit. ... When you start running over 1,000 head in this area, you've got real problems, you've got to scatter out all over.

The discontinuous spatial pattern of the land tenure can have negative implications for diversification via fee hunting:

Our private ground on the mountain is also broken up into just a section here and a section there, and they're not contiguous, they're split up... kind of checkerboard with state land all around it. So, it doesn't really lend itself so you can control the access [for fee hunting].

Because many of Utah's ranchers do not live on the ranch, having discontinuous pastures can make implementing improvements especially difficult. Obviously, ranchers who spend a lot of time each day traveling to and from the ranch, or

Table 1. Comparison of findings about adoption of range management innovations: characteristics identified in the current study vs. those reported in previous research.

\begin{tabular}{lll}
\hline \hline Category of result & Current study & Previous studies \\
\hline Characteristics of innovators & Dependence on ranch income & Rowan \& White 1994 \\
& Commitment to future of ranch & Rowe et al. 2001 \\
& Large social network & Rogers 1995 \\
& On-ranch residence & Not previously identified \\
Works full-time as rancher & Not previously identified \\
& Multi-generation operation & Not previously identified \\
\hline Motivations for adoption & Increase profitability & Rowan \& White 1994 \\
& Improve land stewardship & Not previously identified \\
& Improve gov't relationships & Grigsby 1980' \\
& Improve public relations & Not previously identified \\
\hline Barriers to innovation & Limited time, income & Peterson \& Coppock 2001 \\
Individual factors & Attachment to tradition & Smith \& Martin 1972 \\
& & Rowe et al. 2001 \\
& Grigsby 1980 \\
& Uncertainty about future & Peterson \& Coppock 2001 \\
& Peer attachment to tradition & Grigsby 1980 \\
Social system factors & Design of government programs & Not previously identified \\
& Public land regulations & Not previously identified \\
Political-legal factors & Liability & Not previously identified \\
\hline Grigsby's finding was contradictory to our results; our findings otherwise were consistent with results of all previous studies cited
\end{tabular}

Grigsby's finding was contradictory to our results; our findings otherwise were consistent with results of all previous studies cited. between the different parts of it, will have less time to devote to changing the operation. For these ranchers, innovations that require a continued increase in management input, such as fee hunting or intensive rotational grazing, may not appear to be practical investments.

During 1 interview a barrier was identified that does not fit into the traditional theoretical categories explored as influences on adoption (i.e., characteristics of the individual, innovation, social system, and operation): excessively widespread adoption of the innovation. The fee hunting program in Utah is popular, and interviewees who participate in it emphasized how valuable diversification has been to their ranching operations. However, perceived competition among fee hunting operations was noted as a barrier to income diversification. As one rancher described,

...I have a friend that has a hunting business... and it really took off and he was doing well, but now there's one popped up right next to him... and they're taking a lot of his business. And so, these people are creating competition.

\section{Summary and Implications}

Results demonstrate the applicability of past adoption research to the ranching 
community, while defining new conceptual components that enhance the overall theoretical framework (Table 1). Exploring these new components (i.e., ranch spatial characteristics and characteristics of the political-legal system) may help future researchers further understand adoption among livestock producers.

Our findings affirm that ranchers value the traditional ranching lifestyle, and that innovation adoption exists only among the minority of ranchers in Utah. However, by accounting for known obstacles to adoption, range professionals may be able to facilitate innovative management and thereby improve both the economic and environmental sustainability of ranch operations. Professionals in Utah should be aware that adoption is affected by offranch residences coupled with the dispersed spatial characteristics of Utah ranches. Because of this, what works well in one state may not work as well for Utah.

Innovation appears to be negatively influenced by characteristics of the political-legal system. We found barriers imposed by perceptions of how (1) characteristics of government programs, (2) public land management and government regulations, and (3) liability associated with diversification affect the ability to make management changes. However, these barriers may be lowered by designing information materials to reduce misperceptions. For example, reluctance to diversify the ranch with a recreation enterprise may be reduced if ranchers are provided with clear guidelines for liability protection.

The perception of competition among fee hunting operations deserves special attention. Fee hunting is actively promoted in Utah as a way for ranchers to enhance profitability of their operations. However, if the establishment of additional fee hunting operations creates problems of competition, producers who have already invested in this type of diversification strategy could be harmed. As a result, efforts to encourage ranchers to stay on the land could be rendered ineffective. Further research is needed to quantify the level of competition among fee hunting businesses.

The qualitative approach uncovered the motives and characteristics of Utah ranchers who are adopting range management innovations. Educational materials should emphasize the relevance of novel management approaches to the motivations of innovative producers. Extension agents or others who serve as "change agents" among ranchers can use this information to target producers that are most likely to become early adopters of new management strategies, such as full-time ranchers who expect the ranch to continue for at least one more generation. As Rogers (1995) points out, these individuals introduce unfamiliar management techniques to the social system, allowing the outcomes to be observed by other local ranchers.

\section{Literature Cited}

Babbie, E.A. 1989. The practice of social research, 5th ed. Wadsworth, Belmont, Calif.

Babbie, E. 1999. The basics of social research. Wadsworth, Belmont, Calif.

Bliss, J.C. and J.A. Martin. 1989. Identifying NIPF management motivations with qualitative methods. Forest Sci. 35(2):601-622.

Bogdan, R. and S.J. Taylor. 1975. Introduction to qualitative research methods. John Wiley \& Sons, New York, N.Y.

Bultena, G.L. and E.O. Hoiberg. 1983. Factors affecting farmers' adoption of conservation tillage. J. Soil Water Conserv. 38:281-284.

Buttel, F.H. and L.E. Swanson. 1986. Soil and water conservation: A farm structural and public policy context, p. 26-39. In: S.B. Lovejoy and T.L. Napier (eds.) Conserving soil: Insights from socioeconomic research, Soil Conserv. Soc. Amer, Ankeny, Iowa.

Coppock, D.L. and A.H. Birkenfeld. 1999. Use of livestock and range management practices in Utah. J. Range Manage. 52:7-18.

Downey, H.K. and R.D. Ireland. 1983. Quantitative versus qualitative: Environmental assessment in organizational studies. p. 179-190. In: J. Van Maanen (ed.) Qualitative methodology. Sage Publications, Beverly Hills, Calif.

Glaser, B.G. and A.L. Strauss. 1967. The discovery of grounded theory: Strategies for qualitative research. Aldine Publishing Co., Chicago, Ill.

Grey, A.H. 1978. Mormon settlement in its global context. p. 75-89. In: R.H. Jackson (ed.) The Mormon role in the settlement of the West. Brigham Young University Press, Provo, Utah.

Grigsby, T.L. 1980. Today's riders of the purple sage: Symbols, values, and the cowboy myth. Rangelands 2:93-96.

Henderson, K.A. 1991. Dimensions of choice: A qualitative approach to recreation, parks, and leisure research. Venture Publishing, Inc., State College, Penn.

Kearl, W.G. 1975. Economic and management constraints for livestock production in arid shrublands, p. 116-124. In: D.N. Hyder (ed.) Arid Shrublands, Proc. 3rd Workshop of the United States/Australia Rangelands Panel. Tucson, Ariz.

Knight, R.L., W.C. Gilgert, and E. Marston. 2002. Ranching west of the 100th meridian: Culture, ecology, and economics. Island Press, Washington D.C.
Knight, R.L., G.N. Wallace, and W.E. Riebsame. 1994. Ranching the view: Subdivisions versus agriculture. Conserv. Biol. 9:459-461.

Kreuter, U.P., H.E. Amestoy, D.N. Ueckert, and W.A. McGinty. 2001. Adoption of Brush Busters: Results of Texas county extension survey. J. Range Manage. 54:630-639.

Lacey, J.R., J.R. Wight, and J.P. Workman. 1985. Investment rationale for range improvement practices in Eastern Montana. J. Range Manage. 38:2-6.

Miles, M.B. 1983. Qualitative data as an attractive nuisance: The problem of analysis, $\mathrm{p}$. 117-134. In: J. Van Maanen (ed.) Qualitative methodology. Sage Publications, Beverly Hills, Calif.

Nowak, P.J. and P.F. Korsching. 1983. Social and institutional factors affecting the adoption and maintenance of agricultural BMPs, p. 349-373. In: F.W. Schaller, and G.W. Bailey, (eds.) Agricultural management and water quality. Iowa State Univ. Press, Ames, Iowa.

Patton, M.Q. 1980. Qualitative evaluation methods. Sage Publications, Beverly Hills, Calif.

Peterson, R. and D.L. Coppock. 2001. Economics and demographics constrain investment in Utah private grazing lands. $\mathrm{J}$. Range Manage. 54:106-114.

Rogers, E.M. 1995. Diffusion of innovations, $4^{\text {th }}$ ed. The Free Press, New York, N.Y.

Rowan, R.C. and L.D. White. 1994. Regional differences among Texas rangeland operators. J. Range Manage. 47:338-343.

Rowe, H.I., M. Shinderman, and E.T. Bartlett. 2001. Change on the range. Rangelands 23:6-9.

Saltiel, J., J.W. Bauder, and S. Palakovich. 1994. Adoption of sustainable agricultural practices: Diffusion, farm structure, and profitability. Rural Soc. 59:333-347.

Smith, A.H. and W.E. Martin. 1972. Socioeconomic behavior of cattle ranchers with implications for rural community development in the West. Amer. J. Agr. Econ. 54:217-225.

Stebbins, R.A. 2001. Qualitative research methods: Exploratory research in the social sciences. Sage Publications, Thousand Oaks, Calif.

Strauss, A. and J. Corbin. 1990. Basics of qualitative research: Grounded theory procedures and techniques. Sage Publications, Newbury, Calif.

Yin, R.K. 1994. Case study research, $2^{\text {nd }} \mathrm{ed}$. Sage Publications, Thousand Oaks, Calif. 